\title{
Sports Injury, the Pain Principle, and the Promise of Reform
}

\author{
Don Sabo \\ D’Youville College
}

It has been said that the fish are the last ones to discover the ocean. And so it is with patriarchy. During the 19th century, a few social philosophers in France and England, as well as leading thinkers and activists in the suffrage and women's movement in the United States, began to "perceive" the ocean of patriarchy and to describe its workings and gender politics. Feminisms evolved during the 20th century and culminated in women's studies, feminist theory, and later gender studies. But the recognition of feminist scholarship as bona fide social theory that explains human behavior and social processes has been hobbled by its ideological moorings and presumed lack of scientific rigor. Ironically, it has been scientific method and evidence-based research that have, during the latter 20th century, begun to shore up the explanatory power and theoretical claims of what are now called "gender theories." One application of gender theory has been applied to understanding variations in women's and men's health (Payne, 2006; Sabo, 2005).

In this article I reflect on Mariah Burton Nelson's keynote, "The Damage I Have Done to Myself: Physical Intelligence Among College Athletes" within a sociocultural analysis of sports injury that takes gender relations and male-dominated social organizations (i.e., patriarchy) into account. Within the biomedical model, sports injuries are explained basically as physiological processes. An orthopedic surgeon or athletic trainer brings a clinical sensibility to understanding sports injury. Psychologists work with the emotional facets of sports injury. Sociologists study the institutional contexts and cultural practices that give rise to and surround sports injury. In the end, the injured ankle or arthritic knee is attached to an individual psychology or personal identity that, in turn, develops within a culture and hierarchical gender order. Mariah Burton Nelson's knee injuries and subsequent chronic pain can be partly understood within this larger context.

\section{The Pain Principle}

I argue that the ways that we define and interpret sports injury are deeply rooted in long-standing cultural traditions and patterns of gender relations. The "pain principle" is a pervasive narrative or cluster of meanings that became insinuated

The author is the Director of the Center for Research on Physical Activity, Sport and Health, D'Youville College, 320 Porter Avenue, Buffalo, NY, 14201. 
in western Judeo-Christian cultural traditions (Sabo, 1986). The pain principle is defined as a patriarchal cultural belief that pain is inevitable and that the endurance of pain enhances one's character and moral worth. Pain is regarded as more important than pleasure, and sacrifice is presumed to be required to establish selfworth, social acceptance, and social gains (Sabo, 2004).

The pain principle grew up in synchrony with the development of maledominated social organizations, perhaps as far back as the emergence of agricultural societies. It is no accident that the most pervasive religious image in Christianity is the battered and bleeding Christ, the son of a father god who is sacrificed on the cross to bring salvation to humanity (Eisler, 1988). The biblical story of Abraham also shows how notions of pain and sacrifice are sewn into the lining of patriarchal culture. To demonstrate his obedience and allegiance, Abraham complies with an order by the father god to sacrifice his youngest son. Accompanied by his sons and manservants, he prepares to stab and burn his son on a wooden pyre in the dessert, only to be stopped at the last second by a male angel. These religious accounts illustrate how individual sacrifice and suffering within patriarchal cultures are often extolled in ways that glorify or reinforce the righteousness of prevailing cultural beliefs and, in effect, reflect and reinforce men's relationships within intermale dominance hierarchies. The institution of war provides an additional example. Pain and sacrifice accompany warfare, and it is typically male underlings who are trained and encouraged by superior officers to bear pain and risk wounds or death (sacrifice). Some warriors rise through the ranks unscathed, others are injured, while elite groups of males (inside and outside the military) preserve their rank with its concomitant status and material benefits.

Adages that evoke the pain principle in sport include "No pain, no gain," "Push yourself to the limit," "Sacrifice your body," "Suck it up," "Perform in spite of pain," or "Work through the pain." Toughness is considered a prerequisite for success in sport, and young athletes are often encouraged to "pay the price for victory." Major league baseball manager Sparky Anderson reportedly explained to a player, "Pain don't hurt."

Finally, in western culture sport has long been equated to masculinity (McKay, Messner, \& Sabo, 2000). The denial of pain in sport was seen as a masculine attribute, an earmark of toughness and masculine adequacy (Katz, 2006). The denial of pain has been gendered "masculine" and, concomitantly, the admission of pain has been gendered "feminine." In recent decades, however, women have entered sports in increasing numbers, and the gendered meanings associated with ascetic postures in sport show signs of changing. Mariah Burton Nelson's basketball career and body bear some imprints of the pain principle at work.

\section{Denial of Athlete Pain}

In her formative athletic days, Mariah Burton Nelson kept her pain to herself. Her silence, however, was reflected and reinforced by the larger cultural silences and collective inobservance surrounding the prevalence and personal costs of sports injuries. Those of us who advocate for sport and focus on its positive contributions to youth development and physical well-being have been in denial about athlete pain. We talk about injury, we count injuries, even sometimes glorify injury, but it is the pain that accompanies injury that has been taboo. 
Most athletes do not discuss their pain and, if they do make reference to it, it typically takes the form of a mocking or flippant comment. (For example, "Don't worry, it only hurts when I breathe.") Athletes do not ruminate or reflect that much about pain, even though they might experience it frequently. Unsurprisingly, they do not lean toward enlightened stoicism because athletic competition stresses functions and outcomes more so than philosophical reflection. Traditionally masculine locker-room subcultures have also glorified if not sanctified pain. Real men endure pain and weak or presumably "feminine" men express or give into pain. Fans and sports commentators glorify injured athletes who play "with" pain or "through" pain, and their collective chorus becomes a cloaking device that hides their emotional turmoil and despair of the athletes who actually suffer injury and pain. A recent example would be the media's mawkish admiration of Tiger Woods's protracted suppression of pain as he winced his way to victory in the 2008 U.S. Open.

Until recent decades, researchers typically ignored sports injury and the study of chronic pain among athletes. Few epidemiological studies have calculated the health risks associated with contact sports. In contrast, a sufficient body of research exists for epidemiologists to estimate the relative risks for cirrhosis of the liver or lung cancer from early and/or prolonged use of alcohol or tobacco. Where are the longitudinal research findings that can inform parents, coaches, and athletes about the long-term risks incurred by contact sports for arthritis, chronic back problems, knee pain, or hip replacement surgery? These questions have not been answered because medical, epidemiological, and sport researchers have yet to do the work. I suggest that the lack of analytical research is itself, in part, an expression of a wider cultural denial of athletic pain. It is both admirable and timely, therefore, that Ronald Zernicke called for prospective trials to assess long-term debilitation from sports injury during his keynote address (2009).

\section{Meritocratic Pain}

Athletes aspire and compete for the love of the game, social acceptance, and to climb one ladder or another. In sport, as in all hierarchies, there are always multiple benchmarks of upward mobility (e.g., make the team, make the first team, get to be the captain, win the championship, get the scholarship, be the MVP, become the Olympian or professional athlete, be ensconced in a "hall of fame"). "Good" athletes get ahead, move up, and succeed, ostensibly on their own merits, but also in synchronicity with opportunity and status systems. Individual upward mobility in sport, as in other institutional hierarchies, is largely influenced by the availability of social resources. "Meritocratic pain "occurs when individuals believe that the endurance of pain will help them achieve upward mobility. In the words of the conference theme, it is about "paying the price" to ascend and succeed (Sabo, 2004 , p. 72). Here is where the pain principle melds with the status hierarchies and the political economies of postindustrial capitalism.

Mariah Burton Nelson, aided and abetted by meritocratic pain, was a successful athlete whose body fell beneath the weight of overuse, a love for the game, and competitive zeal. She sacrificed and climbed or, perhaps more accurately, she was raised up while she sacrificed and climbed. Mariah's life history is consistent with 
those of the participants in an in-depth interview study I conducted in the late 1990s. I interviewed a purposive sample of 30 former college athletes, professionals, and Olympians (15 women and 15 men) who self-identified as living in chronic pain that resulted from a catastrophic sports injury or overtraining. For each of these interviewees to keep playing and get to the "next level," symptom denial and an acceptance of risk and suffering were seen as "paying the price" for upward mobility. Both the men and women reported becoming adept at denying their pain and keeping it to themselves. Denial was an inner badge of courage and an outer symbol of accomplishment and dedication. Regardless of gender, they all played in spite of injury, and complied with the mandates of coaches or competition. As Mariah put it in her keynote, "Women (athletes) now run with the suck it up crowd." In short, there were more gender similarities than differences.

In contrast to the above gender similarities, women often saw the links between sports injury and the cultural practices surrounding the denial of pain as gendered. They labeled their own asceticism as "macho" or they loosely tied it to traditional masculinity. Some questioned or chastised themselves for beating themselves up like "the men." Or they pointed to tough coaches who "treated us like the men." As a former swimmer who now has "blown-out shoulders" put it, "The coach made us swim with the men, and he worked us just as hard as the men." Like Mariah, her ritual was to apply ice bags to her shoulders after each workout or competition until, eventually, she could no longer swim. It was as though when women experienced pain and injury during training and competition, at some level they perceived the pain and injury risk as being masculine or as part of the culture of men's sports. In contrast, the male athletes I interviewed did not perceive their chronic pain through a lens that questioned gender assumptions. No critique of traditional masculinity was evident, and taking health risks and enduring pain were deemed integral parts of sport and being an athlete. And yet, both females and males accepted the inevitability of their injuries and pain, and more subtly, its necessary contributions to upward mobility in sport.

Mariah Burton Nelson used her keynote address to present a critical evaluation of sports injury and pain that not only rethinks gender identity but also attempts to redefine sport. She encourages each athlete to "listen to your body" rather than to sacrifice health and physical well-being. In essence, she counsels athletes to pay attention to pain and symptoms rather than to deny them, to be conscious of feeling well instead of blindly pushing their bodies to harmful extremes. This is sage advice, but in the context of research on gender and health behaviors, women might be more receptive to her message than men. Men are more apt than women to deny symptoms of pain and illness and to avoid visiting their physicians or utilizing healthcare services (Courtenay, McCreary, \& Merighi, 2002; Keough \& Herdenfeldt, 2002; Payne, 2006). At the same time, the time may be ripe for her preventive health message.

\section{Sport as a Vehicle for Preventive Health}

Where do we go from here? Do we dismantle the infrastructure of youth sport and intercollegiate sport, pontificate on negative health outcomes of competition, and, in essence, condemn the delivery system for sports injury? The answer is "no." 
The recognition of the prevalence and severity of injury, and the physical and emotional pain that comes with it, should not lead us to see sport as a world to bemoan and reject, but a social realm that we can better understand and transform. Indeed, I believe that we have entered a new phase of evidence-based sport research that promises to help tap the real and potential benefits of sport that can contribute to the health and well-being of youth and young adults. Let me explain the grounds for my optimism.

Critics of youth sports during the 70 s and 80 s decried a variety of its institutional and cultural components (e.g., too much emphasis on competition and winning, the acceptance of aggression and violence, excessive involvement of adults and parents, the suppression of spontaneous and creative play, and racial and gender inequalities). Today, however, many forms of racial and gender segregation in youth sport have been challenged or eliminated. And an increasing body of research that emerged during the 90's strongly suggests that sports can help enhance the physical and emotional health of U.S. children (President's Council on Physical Fitness and Sports, 1997; Sabo, Miller, Melnick, \& Heywood, 2004; Tucker Center for Research on Girls and Women in Sport, 2007). Most recently, the results of a nationwide survey of 3rd-12th grade U.S. children and the parents of 3rd-12th grade children showed that youth athletic participation is associated with general health and body esteem, healthy weight, social relationships, higher quality of life, and educational achievement (Sabo \& Veliz, 2008). In short, I suggest that the growth of evidence-based research on injury prevention and health outcomes in sport can help policymakers and program leaders to better organize and mobilize youth sports and intercollegiate sports in ways that reduce injury risk and augment the probability of favorable health impacts.

During this colloquium we have heard several references to Michael Sokolove's book Warrior Girls: Protecting Our Daughters Against the Injury Epidemic in Women's Sports (2008). Sokolove sounded an alarm about injury and emotional pain in girls' soccer. His warnings struck a chord and his concerns about girls' health should be well taken. He helped break cultural silences about pain and injury that have been obscured in the past by the pain principle. At the same time, however, I have wondered why similar alarms and calls for policy changes have not been raised about boys who play soccer? During the 2005-2006 school year, for example, the Centers for Disease Control's High School Sports-Related Injury Surveillance Study reported that, "although boys' soccer had slightly higher injury rates than girls' soccer and girls' basketball had slightly higher rates than boys' basketball, no statistically significant differences by sex were observed for soccer and basketball" (Centers for Disease Control, 2006). These incidence data, however, do not tell us about the severity or psychosocial toll of the injuries. And as we heard from experts in this Colloquium, women's overall risk for ACL injuries range between 2-6 to 2-10 times greater than their male counterparts (Silvers, 2009; Zernicke, 2009).

I am not trying to rationalize or explain away Sokolove's concerns about injury in girls' soccer. I share these concerns. But I am observing that it was he who "raised the flag" about pain and injury in women's sports and, today, it is Mariah Burton in Nelson, a former woman athlete who is raising awareness now. The question that gnaws at me is why there has not been a similar hue and cry for concern and reform sounded with regards to "warrior boys" and "wounded men" 
who have been felled by injury in sport? Could it be that in sport, as in many families, the cultural norm exists that women rather than men are expected to do the work of physical and emotional healing? Or more positively, perhaps the preventive health concerns surrounding ACL injuries in women's sports will eventually foment greater recognition of ACL injuries in men's sports, just as the women's health movement of the 60's and 70's gave rise to men's health studies during the 80's and 90's (Sabo, 2005).

The critics of pain and injury in men's sports have been rare, and their calls for reform have often been ignored. In 1994 George D. Lundberg, former editor of the Journal of the American Medical Association, for example, called for a ban on boxing in the Olympics and in the United States military. His editorial entreaty, while based on clinical evidence for neurological harm from boxing, was also couched in a wider critique of the exploitative economics of the sport. Today, boxing still flourishes, and sadly, ultimate fighters and women have joined the ranks of boxers who risk trading their healthy brains for wealth and fame. Similarly, as early as 1999, medical researchers documented a significant relationship between concussion history and reduced neuropsychological performance among college football players (Collins et al., 1999). Similarly, a case-control study of amateur soccer players confirmed elevated risk for chronic traumatic brain injury and neuropsychological impairment. These findings have public health implications for men, as well as women, but there has been no major groundswell to change men's sports. The lack of zeal for reform could be related to the fact that the pain principle is more firmly rooted in the culture of men's sports than women's sports, or that the patterns of economic incentive and exploitation are so entrenched within sport's intermale dominance hierarchies. Or, to echo the Old Testament analogy discussed at the outset of this article, the "Abrahams" still have too much to gain from the sacrifice of the "Isaacs."

At this moment of sport history, Mariah Burton Nelson is both victim and visionary. On one hand, she was battered. I think that the title of her address can be misleading_ “The Damage I have Done to Myself." Mariah made individual decisions that helped to seal her physiological fate, but as Jay Coakley (2009) pointed out in his colloquium address, we need to think about the institutional contexts in which individual athletes live. Mariah's trek toward debilitation was facilitated by institutional relations and the cultural denial of pain. And now, like many former athletes, she's paying the price of admission for youthful athletic achievement on a lifelong installment plan. But as a visionary, her counsel to develop "physical intelligence" among athletes and fitness enthusiasts suggests directions to reform sport and individual engagement with physical activity that will foster health rather than debilitation.

Mariah's vision of "physical intelligence" as a vehicle to develop healthaffirmative sport practices also points to the need for similar strategies to be introduced in institutional settings. I was very gratified when Ronald Zernicke (2009) laid out a multidimensional analysis of the etiology of sports injury that included physiological, psychological, and social factors. Dan Gould (2009) extolled the vision of "educational athletics." And Holly Silvers (2009) detailed a program intervention that effectively reduced women athletes' risk for ACL injuries. In short, it could be said that these researchers are extending applications of the concept of "physical intelligence" to wider social sectors of sport. 
There was also a moment at the end of the "Sport and the Injury Epidemic" session when an audience member asked whether the recognition of injury risk in women's sports would somehow "set back Title IX and the trend toward gender equity" in athletics. In this context, Mariah "the visionary" raised a larger question, that is: Will women change sport or will sport change women? In other words, will women help to transform sport into a more body-enhancing and health-affirmative culture? Or will women be assimilated into the traditional masculine sport model that lays primary emphasis on competitive outcomes, conformity to hierarchical priorities, and sacrifice of athlete health if necessary? Today I am also wondering whether women's entrance into athletics is beginning to erode the cultural efficacy of the pain principle and to replace it with an emerging ethic of preventive health. This approach is certainly expressed in the research goal and preventive health agenda of Holly Silvers (2009); that is, educate athletes to reduce ACL injuries among women and to minimize risk for head injury among male athletes.

In conclusion, this colloquium points to a vision of women and men researchers working together and across disciplines to transform sport in ways that make it more of a vehicle to enhance public health. With reference to the overarching question posed by this NCAA Scholarly Colloquium ("Is excellence in sport compatible with good health?"), I suggest that the answer at this point in history-for both women and men athletes - is both yes and no. It is my hope and aspiration that the new paradigm for constructing young people's sports experiences will be grounded in evidence-based research and policies that foster public health rather than in timeworn patriarchal beliefs.

\section{References}

Centers for Disease Control. (2006). Sports-related injuries among high school athletesUnited States, 2005-06 school year. Morbidity and Mortality Weekly Report, 55(38), 1037-1040.

Coakley, J. (2009). From the outside in: Burnout as an organizational issue. A paper presented at the NCAA Scholarly Colloquium, Washington, D.C., January 13.

Courtenay, W.H., McCreary, D.R.Y., \& Merighi, J.R. (2002). Gender and ethnic differences in health beliefs and behaviors. Journal of Health Psychology, 7(3), 219-231.

Collins, M.W., Grindel, S.H., Lovell, M.R., Dede, D.E., Moser, D.J., Phalin, B.R., et al. (1999). Relationship between concussion and neuropsychological performance in college football players. Journal of the American Medical Association, 282, 964-970.

Eisler, R. (1988). The chalice and the blade: Our history, our future. San Francisco: HarperSanFrancisco.

Gould, D. (2009). The sources and consequences of athletic burnout among college athletes. A paper presented at the NCAA Scholarly Colloquium, Washington, D.C., January 13.

Katz, J. (2006). The macho paradox: Why some men hurt women and some men can help. Naperville, IL: Sourcebooks.

Keogh, E., \& Herdenfeldt, M. (2002). Gender coping and the perception of pain. Pain, 97, 195-201.

Lundberg, G.D. (1994). Let's stop boxing in the Olympics and the United States Military. Journal of the American Medical Association, 271(22), 1790. 
Matser, E.J.T., Kessels, A.G., Lezak, M.D., Jordan, B.D., \& Troost, J. (1999). Neuropsychological impairment in amateur soccer players. Journal of the American Medical Association, 282, 971-973.

McKay, J., Messner, M.A., \& Sabo, D. (Eds.). (2000). Masculinities, gender relations, and sport. Thousand Oaks, CA: Sage.

Nelson, M.B. (2009). The damage I have done to myself: Physical intelligence and the lack of same among college athletes. A paper presented at the NCAA Scholarly Colloquium, Washington, D.C., January 13.

Payne, S. (2006). The health of men and women. Malden, MA: Polity.

President's Council on Physical Fitness and Sports. (1997). Physical activity and sport in the lives of American girls: Physical and mental health dimensions from an interdisciplinary approach. Washington, DC: U.S. Department of Health and Human Services.

Sabo, D. (1986). Pigskin, patriarchy and pain. Changing Men: Issues in Gender, Sex and Politics, 16, 24-25.

Sabo, D. (2004). The politics of sports injury: Hierarchy, power and the pain principle. In K. Young (Ed.), Sporting bodies, damaged selves: Sociological studies of sportsrelated injuries (pp. 59-79). London: Elsevier.

Sabo, D., Miller, K., Melnick, M., \& Heywood, L. (2004). Her life depends on it: Sport, physical activity and the health and well-being of American girls. East Meadow, NY: Women's Sports Foundation.

Sabo, D. (2005). The study of masculinities and men's health. In M. Kimmel, J. Hearn, \& R. Connell (Eds.), Handbook of studies on men and masculinities (pp. 326-352). Thousand Oaks, CA: Sage.

Sabo, D., \& Veliz, P. (2008). Go out and play: Youth sports in America. East Meadow, NY: Women's Sports Foundation. www.WomensSportsFoundation.org/GoOutandPlay/

Silvers, H. (2009). Play at your own risk: Sport and the injury epidemic. ACL injury prevention in the female athlete. A paper presented at the NCAA Scholarly Colloquium, Washington, D.C., January 13.

Sokolove, M. (2008). Warrior girls: Protecting our daughters against the injury epidemic in women's sports. New York: Simon and Schuster.

Tucker Center for Research on Girls and Women in Sport. (2007). The 2007 Tucker Center research report. Developing physically active girls: An evidence-based, multidisciplinary approach. University of Minnesota. Minneapolis, MN: Author.

Zernicke, R. (2009). Play at your own risk: Sport and the injury epidemic. A paper presented at the NCAA Scholarly Colloquium, Washington, D.C., January 13. 